Filippo Cademartiri

Ludovico La Grutta

Roberto Malagò

Filippo Alberghina

Willem B. Meijboom

Francesca Pugliese

Erica Maffei

Anselmo Alessandro Palumbo

Annachiara Aldrovandi

Michele Fusaro

Valerio Brambilla

Paolo Coruzzi

Massimo Midiri

Nico R. A. Mollet

Gabriel P. Krestin

\section{Prevalence of anatomical variants and coronary anomalies in 543 consecutive patients studied with 64-slice CT coronary angiography}

Received: 29 May 2007

Revised: 26 September 2007

Accepted: 6 November 2007

Published online: 2 February 2008

(C) The Author(s) 2007

F. Cademartiri · E. Maffei ·

A. A. Palumbo · A. Aldrovandi .

M. Fusaro

Department of Radiology and

Cardiology, Azienda Ospedaliero-

Universitaria di Parma,

Parma, Italy

F. Cademartiri · L. La Grutta -

R. Malagò · F. Alberghina ·

W. B. Meijboom · F. Pugliese

A. A. Palumbo - N. R. A. Mollet .

G. P. Krestin

Department of Radiology and

Cardiology, Erasmus Medical Center,

Rotterdam, The Netherlands

L. La Grutta · F. Alberghina •

M. Midiri

Department of Radiology,

University of Palermo,

Palermo, Italy

R. Malagò

Department of Radiology,

University of Verona,

Verona, Italy
V. Brambilla $\cdot$ P. Coruzzi

Cardiovascular Rehabilitation Unit,

Don Gnocchi ONLUS,

Parma, Italy

F. Cademartiri $(\square)$

Non-invasive Cardiovascular Imaging

Unit, Department of Radiology,

Azienda Ospedaliero-Universitaria di

Parma,

Via Gramsci, 14,

43100, Parma, Italy

e-mail: filippocademartiri@hotmail.

com

Tel.: +39-521-703222

Fax: $+39-521-703630$

\begin{abstract}
The aim of our study was to assess the prevalence of variants and anomalies of the coronary artery tree in patients who underwent 64-slice computed tomography coronary angiography (CT-CA) for suspected or known coronary artery disease. A total of 543 patients (389 male, mean age $60.5 \pm 10.9$ ) were reviewed for coronary artery variants and anomalies including post-processing tools. The majority of segments were identified according to the American Heart Association scheme. The coronary dominance pattern results were: right, $86.6 \%$; left, 9.2\%; balanced, $4.2 \%$. The left main coro-
\end{abstract}

nary artery had a mean length of $112 \pm 55 \mathrm{~mm}$. The intermediate branch was present in the $21.9 \%$. A variable number of diagonals (one, $25 \%$; two, $49.7 \%$; more than two, $24 \%$; none, $1.3 \%$ ) and marginals (one, $35.2 \%$; two, $46.2 \%$; more than two, $18 \%$; none, $0.6 \%$ ) was visualized. Furthermore, CT-CA may visualize smaller branches such as the conus branch artery $(98 \%)$, the sinus node artery $(91.6 \%)$, and the septal branches $(93 \%)$. Single or associated coronary anomalies occurred in $18.4 \%$ of the patients, with the following distribution: 43 anomalies of origin and course, 68 intrinsic anomalies (59 myocardial bridging, nine aneurisms), three fistulas. In conclusion, 64-slice CT-CA provides optimal visualization of the variable and complex anatomy of coronary arteries because of the improved isotropic spatial resolution and flexible post-processing tool.

Keywords Coronary artery circulation - Multislice computed tomography · Anatomical variants · Anomalies 


\section{Introduction}

Since the beginning of the 1990s, a variety of non-invasive techniques have been introduced in coronary artery imaging in an attempt to replace invasive conventional coronary angiography (CCA). These techniques have shown promising results, although they were considered inadequate for large-scale clinical implementation. Furthermore, advanced modalities such as magnetic resonance (MR) and electron-beam computed tomography (EBCT) are still not widely available on the territory [1-6]. The introduction of multislice computed tomography coronary angiography (MSCT-CA) allowed the detection of significant coronary artery stenosis. Improved performance of 64-slice CT equipment, characterized by isotropic spatial resolution and faster temporal resolution, provided a valid alternative to CCA in selected patient populations [7-11].

MSCT-CA is currently considered the ideal tool to threedimensionally visualize the complex and tortuous anatomy of coronary arteries $[12,13]$. Previous studies with fourand 16-slice CT-CA demonstrated that anomalous coronary arteries may be defined [14-16]. However, to the best of our knowledge, 64-slice studies with large patient series have not yet been published. In the present study, a large patient population who underwent 64 -slice CT-CA was reviewed to assess the prevalence of coronary artery variants and anomalies.

\section{Materials and methods}

Population

A total of 543 consecutive patients (389 male, 154 female, mean age $60.5 \pm 10.9$, range $21-87$ years), who underwent 64-slice CT-CA from $27 / 07 / 2004$ to $28 / 02 / 2006$ in our department, were reviewed for coronary artery variants and anomalies. The majority of patients $(n=476)$ were scheduled for CCA because of suspected or known coronary artery disease (CAD). The other 67 patients were addressed to 64-slice MSCT-CA after CCA to determine the three-dimensional image of a suspected origin or course anomaly. The indication for MSCT-CA were: atypical angina $(n=111)$, typical angina with inconclusive stress test $(n=162)$, presence of risk factors and high risk of major coronary events $(n=46)$, proximal stent patency follow-up $(n=112)$ and by-pass patency follow-up $(n=45)$. The Institutional Review Board approved the study protocol.

CT scan and reconstruction parameters

All examinations were performed with a 64-slice CT scanner (Sensation 64, Siemens, Forcheim, Germany) with
Table 1 Our population resulted heterogeneous because of the multiethnic Dutch population

\begin{tabular}{ll}
\hline Ethnic group & $\%(n)$ \\
\hline The Netherlands & $88.95(483)$ \\
Middle East Asia & $3.31(18)$ \\
South-East Asia & $2.94(16)$ \\
East Europe & $1.84(10)$ \\
South Europe & $1.10(6)$ \\
South America & $0.92(5)$ \\
Africa & $0.92(5)$ \\
\hline
\end{tabular}

the following parameters: slices/collimation $32 / 0.6 \mathrm{~mm}$, rotation time $330 \mathrm{~ms}$, effective temporal resolution (with $180^{\circ}$ algorithm) $165 \mathrm{~ms}, 120 \mathrm{kv}, 900 \mathrm{mAs}$, table feed $/ \mathrm{s}$ $11.63 \mathrm{~mm}$, effective slice thickness $0.6 \mathrm{~mm}$, reconstruction increment $0.3 \mathrm{~mm}$, field of view (FOV) $140-180 \mathrm{~mm}$, isotropic voxel resolution of $0.4 \times 0.4 \times 0.4 \mathrm{~mm}$.

Patients with heart rate $>70 \mathrm{bpm}$ received $100 \mathrm{mg}$ of metoprolol per os $1 \mathrm{~h}$ prior the examination. A bolus of $100 \mathrm{ml}$ of high iodinated contrast material $(400 \mathrm{mg} / \mathrm{ml}$ iomeprol, Iomeron 400, Bracco, Milan, Italy) was injected into an antecubital vein of the right arm with a flow rate of $5 \mathrm{ml} / \mathrm{s}$, followed by a 40-ml saline chaser. A bolus-tracking technique was used for the synchronization between arterial passage of contrast material and MSCT-CA.

Table 2 Segments visualized according to the American Heart Association classification

\begin{tabular}{ll}
\hline Segments & $\%(n)$ \\
\hline 1 & $99.8(542)$ \\
2 & $99.3(539)$ \\
3 & $97.8(531)$ \\
4 & $92.4(502)$ \\
5 & $95.9(521)$ \\
6 & $100(543)$ \\
7 & $100(543)$ \\
8 & $97.8(531)$ \\
9 & $98.7(536)$ \\
10 & $73.7(400)$ \\
11 & $100(543)$ \\
12 & $99.4(540)$ \\
13 & $97.2(528)$ \\
14 & $64.3(349)$ \\
15 & $72.4(393)$ \\
$16^{\text {a }}$ & $21.9(119)$ \\
\hline
\end{tabular}

${ }^{\text {a Segment }} 16$ refers to the intermediate branch 
Data were reconstructed by retrospective gating in enddiastolic phase (from -300 to $-450 \mathrm{~ms}$ before the peak of the subsequent $\mathrm{R}$ wave) or end-sistolic phase to better image the right coronary artery (RCA).

Image and data analysis

All CT examinations were reviewed by three radiologists (L.L.G., R.M. and F.A.) with a level 3 expertise in cardiac CT [17], who loaded the datasets off-line into a dedicated workstation (Leonardo, Siemens, Germany). A total number of 559 examinations were performed and only 13 scans were considered not assessable by the readers in consensus due to poor image quality (severe breathing, triggering or motion artefacts).

All data were analysed with post-processing tools such as multiplanar reconstructions (MPR), curved MPR

Table 3 Prevalence of coronary artery variants $(R C A$ right coronary artery, $L A D$ left anterior descending artery, $L C X$ left circumflex, $L M$ left main, $N D$ not detected)

\begin{tabular}{|c|c|c|}
\hline Variants & & Patients $\%(n)$ \\
\hline \multirow[t]{4}{*}{ Conus branch } & From proximal RCA & $64.1(348)$ \\
\hline & From ostial RCA & $22.3(121)$ \\
\hline & From aorta & $11.6(63)$ \\
\hline & ND & $2(11)$ \\
\hline \multirow[t]{6}{*}{ Sinus node artery } & From RCA & $65.4(355)$ \\
\hline & From LCX & $16.6(90)$ \\
\hline & From RCA and LCX & $9.2(50)$ \\
\hline & $\begin{array}{l}\text { From LCX and } \\
\text { pulmonary artery }\end{array}$ & $0.2(1)$ \\
\hline & From aorta & $0.2(1)$ \\
\hline & ND & $8.4(46)$ \\
\hline \multirow[t]{3}{*}{ LM length } & $<1 \mathrm{~cm}$ & $41.6(226)$ \\
\hline & $1-2 \mathrm{~cm}$ & $47.3(257)$ \\
\hline & $>2 \mathrm{~cm}$ & $7(38)$ \\
\hline Intermediate branch & & $21.9(119)$ \\
\hline \multirow{4}{*}{$\begin{array}{l}\text { Diagonal branches } \\
\text { from LAD }\end{array}$} & ND & $1.3(7)$ \\
\hline & 1 & $25(136)$ \\
\hline & 2 & $49.7(270)$ \\
\hline & $>2$ & $24(130)$ \\
\hline $\begin{array}{l}\text { Septal branches } \\
\text { from LAD }\end{array}$ & & $93(505)$ \\
\hline \multirow{4}{*}{$\begin{array}{l}\text { Marginal branches } \\
\text { from LCX }\end{array}$} & ND & $0.6(3)$ \\
\hline & 1 & $35.2(191)$ \\
\hline & 2 & $46.2(251)$ \\
\hline & $>2$ & $18(98)$ \\
\hline
\end{tabular}

(cMPR), maximum intensity projections (MIP), and volume rendering (VR) to three-dimensionally image the complex anatomy of the coronary artery tree. Disagreement was solved by a consensus reading. Segments were classified according to the American Heart Association (AHA) scheme. Variants considered were: the coronary dominance (right, left, balanced), the variable origin of the conus branch and sinus node artery, the left main (LM) length, the presence of the intermediate branch, the number of diagonal and marginal branches. Anomalies of origin and course, intrinsic coronary anomalies (myocardial bridging, aneurisms $>1.5 \mathrm{~mm}$ ) and termination anomalies (fistulas) were checked. Prevalence data of single coronary artery variants and anomalies were collected.

\section{Results}

Our cohort results were heterogeneous because of the multi-ethnic Dutch population (immigrants $11 \%$, Table 1).

Most of coronary segments were identified, although with a variable rate due to different diameters (Table 2). The anatomical variants of the coronary artery tree are extremely frequent (Table 3 ). According to the literature, the dominance was right in $86.6 \%(n=470)$, left in $9.2 \%$ $(n=50)$, balanced in $4.2 \%(n=23)$ [18]. The LM trunk



Fig. 1 a LM length. b The separate origin of the LAD and LCX might cause technical difficulties during coronary angioplasty due to poor visualization. $\mathbf{c}-\mathbf{e}$ The LM may present variable length 
(segment 5) presented a variable length (mean $112 \pm$ $55 \mathrm{~mm}$, range $17-601 \mathrm{~mm}$, median $106 \mathrm{~mm}):<1 \mathrm{~cm}(n=$ $226,41.6 \%), 1-2 \mathrm{~cm}(n=257,47.3 \%)$, and $>2 \mathrm{~cm}(n=38$, $7 \%$ ) (Fig. 1). The LM trunk was absent in 22 cases $(4.1 \%)$ due to split origin of the left coronary artery (LCA) $(n=18$, $3.3 \%)$ or other origin anomalies $(n=4,0.7 \%)$. A variable number of diagonal branches was observed: one diagonal branch in 136 cases (25\%), two diagonal branches in 270 cases $(49.7 \%)$, and more than two in 130 cases $(24 \%)$ (Fig. 2). No diagonal branches were visualized in just seven cases $(1.3 \%)$. Marginal branches of the left circumflex (LCX) artery were observed in the $99.4 \%(n=540)$ :

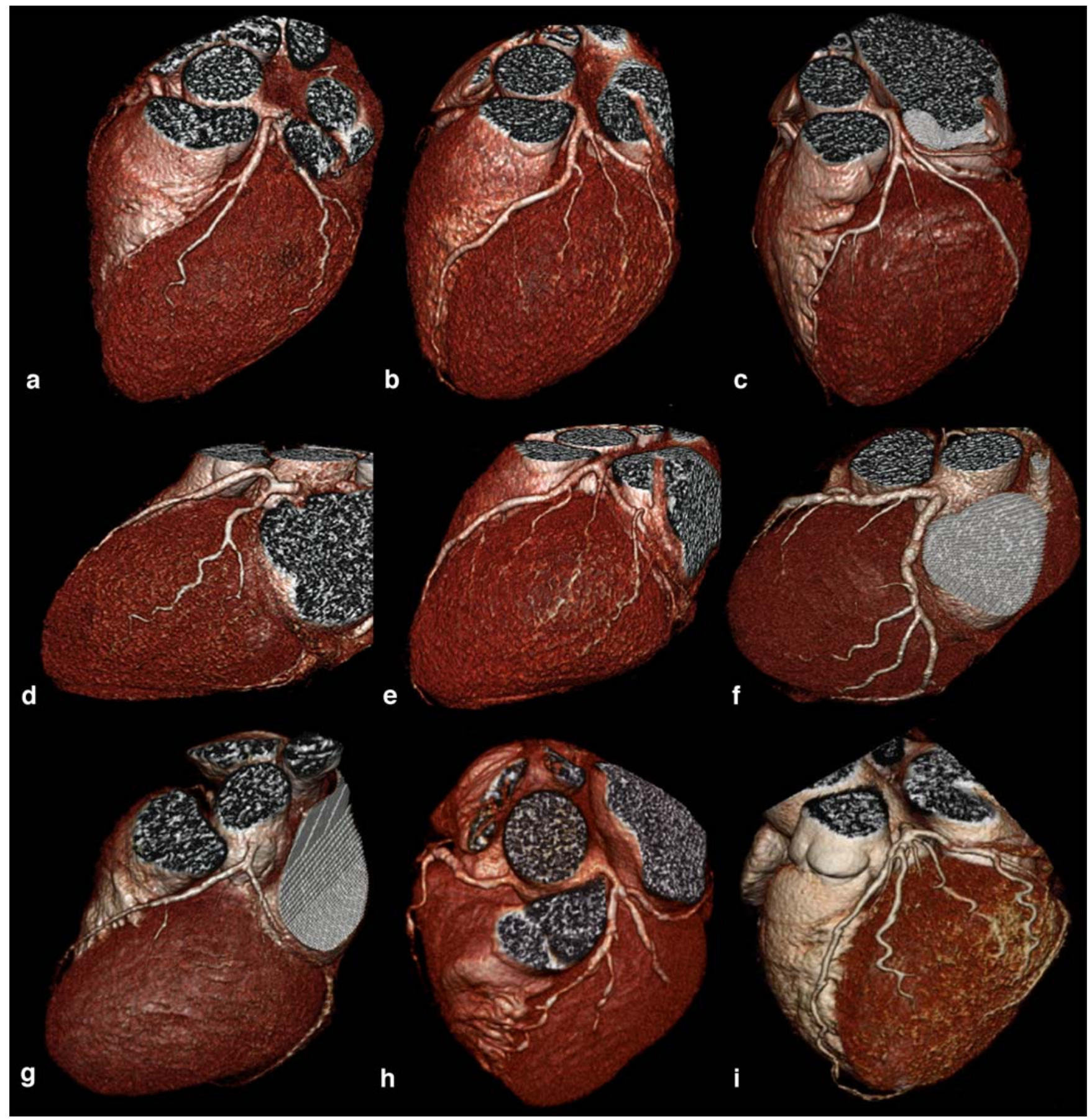

Fig. 2 Variable number and course of diagonal $(\mathbf{a}-\mathbf{c})$ and marginal branches $(\mathbf{d}-\mathbf{f})$. The intermediate branch courses along the anterior wall of the left ventricle with a variable pattern $(\mathbf{g}-\mathbf{i})$ 
one in 191 cases $(35.2 \%)$, two in 251 cases $(46.2 \%)$, and more than two in 98 cases (18\%) (Fig. 2).

When the intermediate branch supplies the vascularization of the antero-lateral wall of the left ventricle, a decreased number of diagonal branches (segments 9 and 10) was observed: one, $38.6 \%$; two, $43.7 \%$; more than two, $14.3 \%$; none, $3.4 \%$ (Fig. 2).

Furthermore, CT-CA may visualize smaller branches, such as the conus branch artery $(532 / 543,98 \%)$, the sinus node artery $(497 / 543,91.6 \%$ ), and the septal branches $(505 / 543,93 \%)$. The conus branch artery may arise from the right coronary artery (RCA) $(64.1 \%)$, in proximity with the RCA ostium $(22.3 \%)$ or from the aorta $(11.6 \%)$. The sinus node artery may originate from the RCA $(355 / 543$, 65.4\%), from LCX $(90 / 543,16.6 \%)$, from RCA and LCX $(50 / 543,9.2 \%)$, from LCX and pulmonary artery $(0.2 \%)$, or from aorta (0.2\%) (Fig. 3).

Coronary anomalies were observed in the $18.4 \%$ of our population $(n=100)$. Patients presented single or associated coronary anomalies (Table 4).

Single or multiple myocardial bridging was visualized in 59 patients (10.9\%) (Fig. 4). Forty-three anomalies of origin and course were found with the following distribu- tion: absence of left main artery occurred in 18 patients (3.3\%), origin anomalies of the RCA and the LCA caused by rotation of the aortic root between $45^{\circ}$ and $90^{\circ}$ (with normal coronary origin from the sinuses of Valsalva) in 14 patients $(2.6 \%)$, anomalies of origin and course (with anomalous origin from the sinuses of Valsalva) in eight patients $(1.5 \%)$, early take-off of the posterior descending artery in three patients $(0.5 \%)$. The anomalies of origin and course encountered were: three retroaortic LCX (two arising from RCA, one from the right sinus of Valsalva), two inter-arterial LCAs from RCA, two inter-arterial RCAs from the left sinus of Valsalva, one septal RCA from left sinus of Valsalva (Fig. 5).

Coronary aneurisms $(>1.5 \mathrm{~mm}$, if compared with the normal vessel diameter) were identified in nine patients $(1.6 \%)$ (Fig. 6). Coronary fistulas were observed in three patients $(0.5 \%)$ (Fig. 7$)$.

\section{Discussion}

The wrong interpretation of a coronary variant or anomaly might cause technical difficulties during interventional

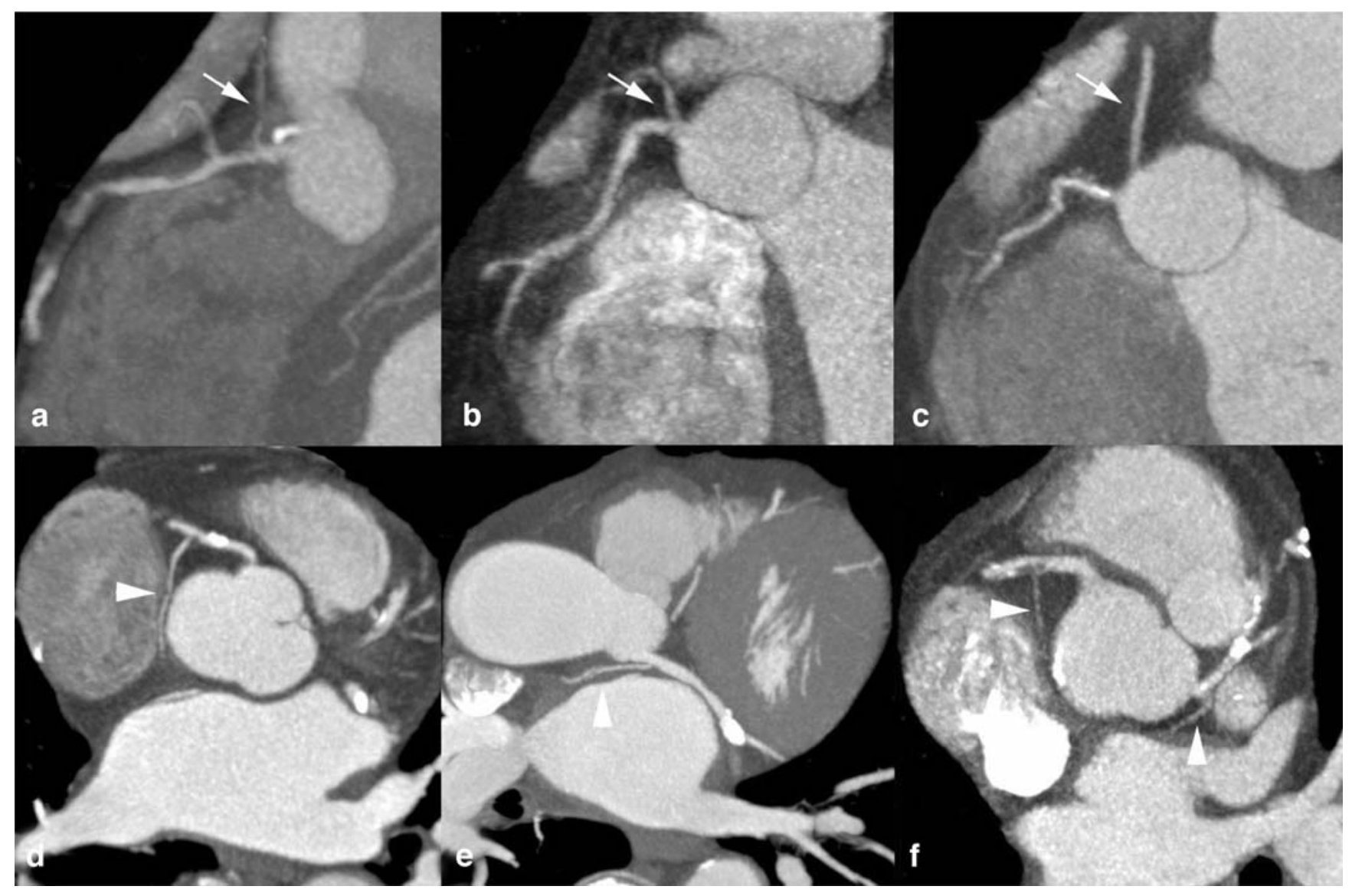

Fig. 3 The variable origin of the conus branch artery (arrow): from RCA (a), in proximity with the ostium (b), and from aorta (c). The variable origin of the sinus node artery (arrowhead): from RCA (d), from LCX (e), or both pathways may be present (f) 
Table 4 Prevalence of coronary artery anomalies ( $L M$ left main artery, $P D A$ posterior descending artery)

\begin{tabular}{ll}
\hline Coronary anomalies & Patients \% $(n)$ \\
\hline Myocardial bridging & $10.9(59)$ \\
Absent LM & $3.3(18)$ \\
Rotation of the aortic root with normal coronary & $2.6(14)$ \\
origin from the sinuses of Valsalva & \\
Coronary aneurysms & $1.6(9)$ \\
Anomalies of origin and course & $1.5(8)$ \\
Fistulas & $0.5(3)$ \\
Early take-off of PDA & $0.5(3)$ \\
\hline
\end{tabular}

procedures or lead to clinical misdiagnosis or major complications might occur during graft surgery. The need for an accurate anatomical evaluation of the coronary artery tree is relevant during angioplasty, due to revascularization purposes [19]. Coronary anomalies are often asymptomatic and may be accidentally discovered. Given the increase of interventional procedures, the detection of coronary anomalies is becoming of major clinical importance [20]. The coronary anomalies cannot be considered just rare aspects because they may often lead to relevant clinical consequences [21].

In an attempt to clarify the variability of the coronary artery tree, Angelini et al. [18] proposed these definitions: normal, any morphological feature observed in $>1 \%$ of an unselected population; normal variant, an alternative, relatively unusual, morphological feature seen in $>1 \%$ of the population; and anomaly, a morphological feature (number of ostia, proximal course, termination) rarely encountered $(<1 \%)$ in the general population. However, the incidence of coronary anomalies is relevant not only for conceptual and educational purposes but, more importantly, for public health issues, given that $5.6 \%$ of the total American population could have some kind of coronary anomaly [18]. Moreover, the $19 \%$ of sudden deaths in young athletes are related to these anomalies [22]. That is a reason why the diagnosis of coronary anomalies should be a healthcare priority.

To date, despite some limitations, CCA has been the "gold standard" for the diagnosis of coronary anomalies. Selective catheterization and subsequent interpretation of vessel anatomy may be difficult in CCA because the operator is not aware of an atypical location of the vessel orifice. Therefore, the diagnosis of a coronary anomaly is often established on the impossibility of finding the coronary arteries in their normal anatomical position. Finally, interpretation of the courses of anomalous coronary arteries may be erroneous because CCA is twodimensional and cannot provide enough information about the complex three-dimensional vessel anatomy $[18,23$,
24]. The study with the largest number of cases, performed in North America at the Cleveland Clinic on 126,595 patients who underwent coronary angiography, reported a $1.3 \%$ incidence [25]. In recent years, other techniques in cardiologic diagnostic imaging have been developed, such as trans-thoracic echocardiography (TTE), trans-oesophageal echocardiography (TEE), magnetic resonance angiography (MRA), EBCT and MSCT [1-4].

TTE, which is used mainly in paediatric radiology, does not always provide reliable diagnostic results. When performed on adult patients, it proves difficult to obtain diagnostic images owing to the interposition of the bones of the ribcage (ribs and sternum), pulmonary parenchyma and subcutaneous adipose tissue $[5,26]$.

Data reported in the literature suggest that TEE is more sensitive than TTE in identifying coronary anomalies and assessing their course, although it remains an invasive technique (i.e. insertion of a probe down the oesophagus and a varying degree of sedation according to patient tolerance required to perform the examination) characterised by a significant level of operator dependence and therefore impossible to perform as a screening test [6]. In addition, both echocardiography techniques are able to assess only the proximal tract of the coronary arteries, and therefore, their diagnostic capabilities are limited to only a part of coronary arteries [6].

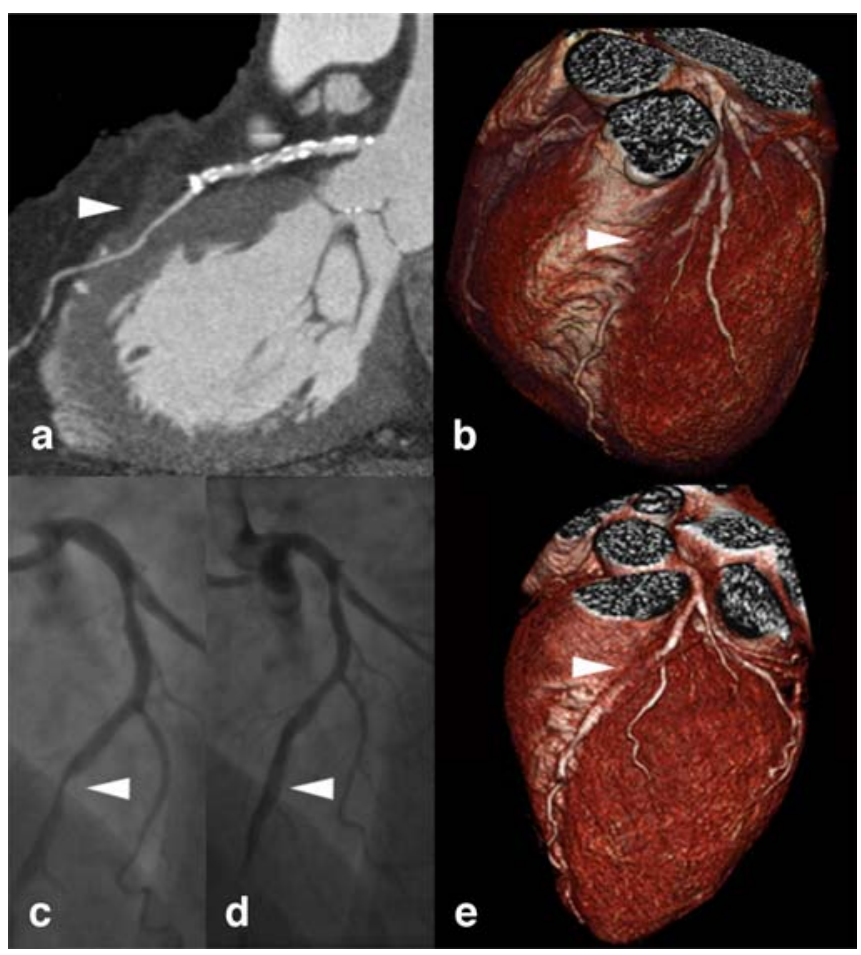

Fig. 4 Examples of myocardial bridging (arrowhead). Myocardial bridging of mid-LAD displayed by MPR (a) and VR (b) images. Another case of myocardial bridging depicted by conventional angiogram in systole (c), not visualized in diastolic image (d), and clearly displayed by VR image (e) 


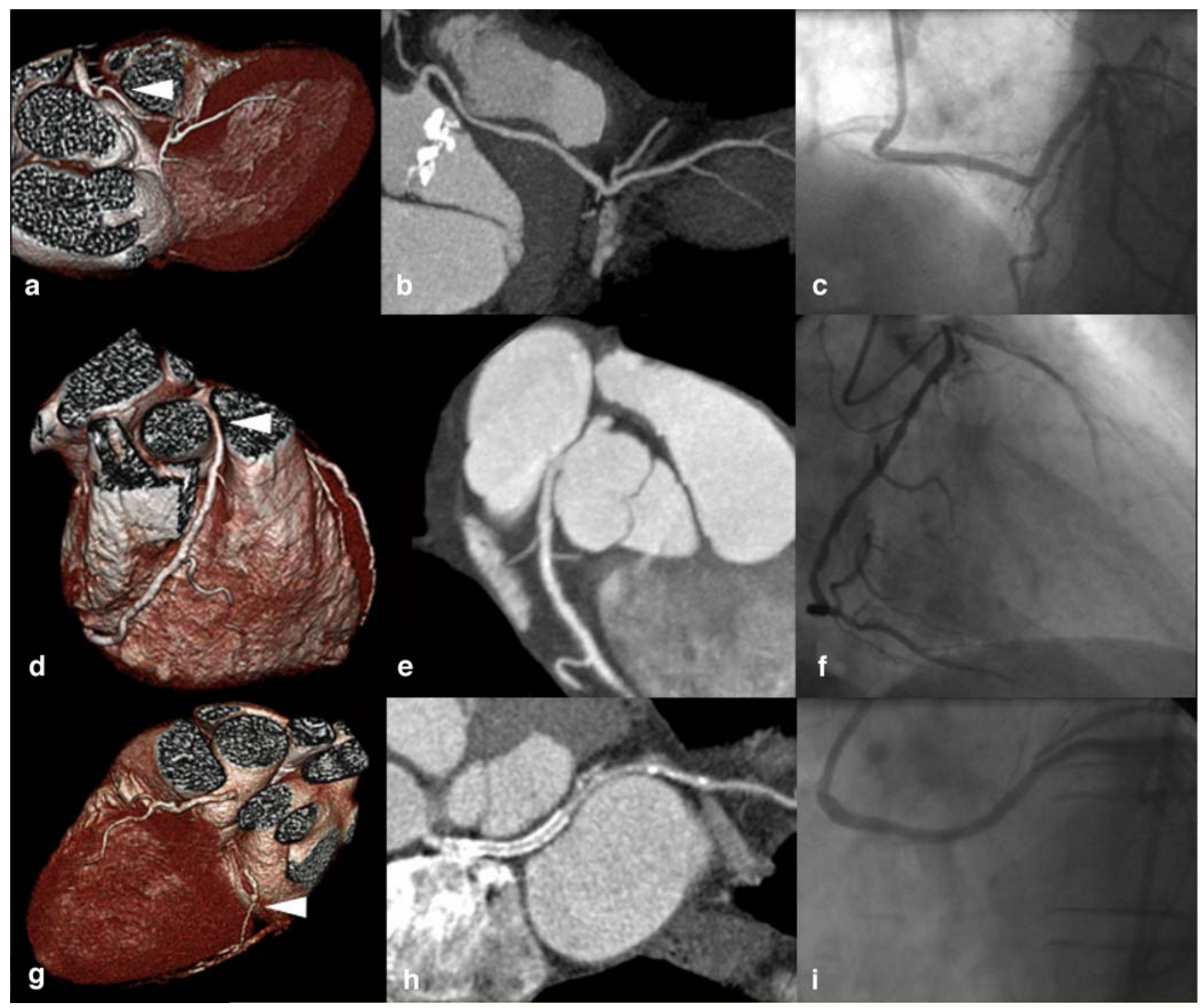

Fig. 5 Anomalies of origin and course (arrowhead). VR (a) and MIP (b) images of a LCA arising from the RCA with a septal course as confirmed by conventional angiogram (c). VR (d) and MIP (e) images of a RCA arising from the left sinus of Valsalva with an

MRA is a highly promising technique since no ionising radiation is used. In the study of the origin of the coronary arteries, MRA can provide more complete information than CCA, particularly in patients with other concomitant congenital cardiac anomalies $[1,27]$. The main limitation of MRA is incomplete visualisation of the coronary vessels, particularly their distal tracts. This limits the diagnostic capabilities for the assessment of fistulas, the origin of coronary arteries other than the aortic sinuses (i.e. from the pulmonary artery) and collateral vessels. However, MRA provides optimal functional assessment of complex congenital heart disease including anomalies of great vessels, and cardiac chambers and valves (the procedures may include evaluation of ventricular mass interarterial course, and corresponding conventional angiogram (f). VR (g) and cMPR (h) images of a stented retroaortic LCX arising from the right sinus of Valsalva and corresponding conventional angiogram (i)

and volumes, quantification of valvular disease, and contrast enhancement) [12].

Ropers et al. [2] firstly studied the ability of contrastenhanced EBCT to identify anomalous coronary arteries and their course with good accuracy. Recent advances in MSCTCA equipments have continuously improved the quality of non-invasive coronary artery imaging. Various studies have demonstrated a high accuracy of coronary angiography with MSCT-CA for the diagnosis of CAD. In particular, the high negative predictive value of 64-slice CT allows to reliably exclude significant coronary artery stenoses [7-11]. Given the high sensitivity and negative predictive value of the technique, MSCT could represent a non-invasive alternative to CCA in patients prior to cardiac valve surgery. By 




Fig. 6 Examples of coronary aneurisms. Aneurisms of LCX and LAD displayed by VR (a) and MIP (b) images, and corresponding conventional angiogram (c). Aneurisms of the RCA depicted by VR

image (d) and vessel tree isolation (e), confirmed by the conventional angiogram (f)

According to literature data, the dominance was right in $86.6 \%(n=470)$, left in $9.2 \%(n=50)$ and balanced in $4.2 \%$ $(n=23)[18]$. The majority of coronary segments was identified according to the American Heart Association scheme.

The intermediate branch was present in 119 patients $(21.9 \%)$, slightly less than reported in the literature [34]. However, the need for reporting the intermediate branch is stressed by the correlation between its presence and the decreased number of diagonal branches observed.

Furthermore, the septal branches of the left anterior descending artery (LAD) were detected in the 93\% $(505 / 543)$. The opportunity of reporting septal branches of LAD must be taken into account because of the hemodinamic relevance of these vessels.

The prevalence of coronary anomalies was estimated at the $18 \%(100 / 543)$ in our population. This prevalence rate is higher than reported in the literature. However, our department is a major centre for cardiovascular pathologies and many patients were enrolled in non-invasive cardiovascular research projects. Myocardial bridging occurred in the $10.9 \%$, a prevalence more comparable with autopsy rates, than with angiographic series [35]. The split of LCA also had a prevalence higher than reported in the literature [18]. Eighty-five patients with not significant CAD presented 14 coronary anomalies (16.5\%). Four hundred
Another classification was reported by the BARI group with emphasis to the coronary dominance pattern [31-33]. 


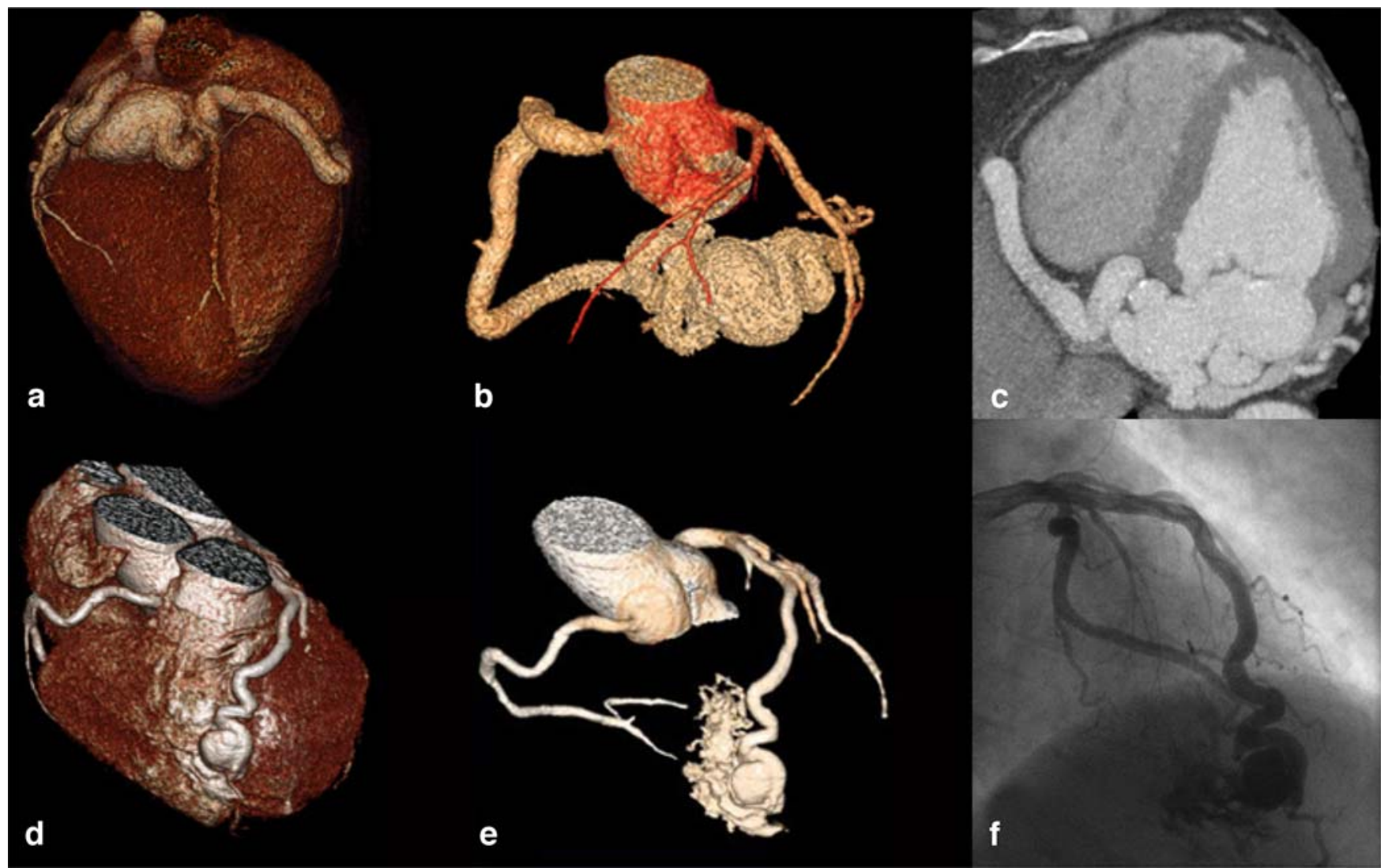

Fig. 7 Abnormal termination of coronary arteries. Fistula between the RCA and the coronary sinus depicted by VR (a), coronary tree isolation (b), and MPR images (c). Fistula between the LAD and the

right ventricle displayed by VR (d) and coronary tree isolation images (e), and corresponding conventional angiogram (f) and fifty-eight patients with significant CAD (with $>50 \%$ stenosis, during stent or by-pass follow-up) presented 86 coronary anomalies $(18.8 \%)$. Therefore, the prevalence was similar in the two groups. However, a bias is given by the fact that 67 patients were addressed to 64-slice CT-CA after CCA to determine the three-dimensional imaging of a suspected anomaly. After excluding these 67 patients, the prevalence of coronary anomalies was higher in the CAD patients $(11.4 \%$ vs $4.2 \%)$. The prevalence of myocardial bridging resulted higher in the $\mathrm{CAD}$ group $(7.4 \%$ vs $2.8 \%)$.

There are several limitations in our study. The first one is inherent to the heterogeneous population consisting of various ethnic groups (immigrants $11 \%$ ) with a substantial age range (21-87 years). The age may affect the development of the collateral vascularization and influence the percentage of segments visualized. A second limitation is related to the high prevalence of origin anomalies, due to the fact that 67 patients were addressed to 64-slice CT-CA after CCA to determine the three-dimensional imaging of a suspected anomaly. As opposed to MRA, which also permits the non-invasive evaluation of coronary anomalies (proximal tracts), MSCT-CA requires radiation and a contrast agent. However, the high spatial and temporal resolution make it reasonable to use MSCT-CA as one of the first-choice imaging modalities in the work-up of known and suspected coronary anomalies $[12,13]$. The high radiation exposure should be a matter of concern and debate in young patients. In these patients, the first-choice imaging modality could be MRA. In the case of suspected complex congenital heart disease (including anomalies of great vessels, and cardiac chambers and valves), the use of MRA would be highly advisable, since the optimal evaluation of ventricular and valvular function is provided $[12,13]$.

Compared with 16-slice CT-CA, 64-slice CT-CA provides improved temporal resolution and isotropic spatial resolution which allow optimal three-dimensional visualization of the variable and complex anatomy of coronary arteries. Sixty-four-slice CT-CA may non-invasively define normal anatomical variants from potentially dangerous anomalies and support the clinical management of referring cardiologists and cardiac surgeons.

Open Access This article is distributed under the terms of the Creative Commons Attribution Noncommercial License which permits any noncommercial use, distribution, and reproduction in any medium, provided the original author(s) and source are credited. 


\section{References}

1. McConnell MV, Ganz P, Selwyn AP, Li W, Edelman RR, Manning WJ (1995) Identification of anomalous coronary arteries and their anatomic course by magnetic resonance coronary angiography. Circulation 92:3158-3162

2. Ropers D, Moshage W, Daniel WG, Jessl J, Gottwik M, Achenbach S (2001) Visualization of coronary artery anomalies and their anatomic course by contrast-enhanced electron beam tomography and three-dimensional reconstruction. Am J Cardiol 87:193-197

3. Davis JA, Cecchin F, Jones TK, Portman MA (2001) Major coronary artery anomalies in a pediatric population: incidence and clinical importance. J Am Coll Cardiol 37:593-597

4. Giannoccaro PJ, Sochowski RA, Morton BC, Chan KL (1993) Complementary role of transoesophageal echocardiography to coronary angiography in the assessment of coronary artery anomalies. Br Heart J 70:70-74

5. Gaither NS, Rogan KM, Stajduhar K, Banks AK, Hull RW, Whitsitt T, Vernalis MN (1991) Anomalous origin and course of coronary arteries in adults: identification and improved imaging utilizing transesophageal echocardiography. Am Heart J 122:69-75

6. Fernandes F, Alam M, Smith S, Khaja F (1993) The role of transesophageal echocardiography in identifying anomalous coronary arteries. Circulation 88:2532-2540

7. Mollet NR, Cademartiri F, van Mieghem CA, Runza G, McFadden EP, Baks T, Serruys PW, Krestin GP, de Feyter PJ (2005) High-resolution spiral computed tomography coronary angiography in patients referred for diagnostic conventional coronary angiography. Circulation 112:2318-2323

8. Leschka S, Alkadhi H, Plass A, Desbiolles L, Grunenfelder J, Marincek B, Wildermuth S (2005) Accuracy of MSCT coronary angiography with 64-slice technology: first experience. Eur Heart J 26:1482-1487

9. Raff GL, Gallagher MJ, O’Neill WW, Goldstein JA (2005) Diagnostic accuracy of noninvasive coronary angiography using 64-slice spiral computed tomography. J Am Coll Cardiol 46:552-557

10. Pugliese F, Mollet NR, Runza G, van Mieghem C, Meijboom WB, Malagutti P, Baks T, Krestin GP, Defeyter PJ, Cademartiri F (2006) Diagnostic accuracy of non-invasive 64-slice CT coronary angiography in patients with stable angina pectoris. Eur Radiol 16:575-582
11. Mühlenbruch G, Seyfarth T, Soo CS, Pregalathan N, Mahnken AH (2007) Diagnostic value of 64-slice multidetector row cardiac CTA in symptomatic patients. Eur Radiol 17:603-609

12. Hendel RC, Patel MR, Kramer CM, Poon M, Hendel RC, Carr JC, Gerstad NA, Gillam LD, Hodgson JM, Kim RJ, Kramer CM, Lesser JR, Martin ET, Messer JV, Redberg RF, Rubin GD, Rumsfeld JS, Taylor AJ, Weigold WG, Woodard PK, Brindis RG, Hendel RC, Douglas PS, Peterson ED, Wolk MJ, Allen JM, Patel MR, American College of Cardiology Foundation Quality Strategic Directions Committee Appropriateness Criteria Working Group, American College of Radiology, Society of Cardiovascular Computed Tomography, Society for Cardiovascular Magnetic Resonance, American Society of Nuclear Cardiology, North American Society for Cardiac Imaging, Society for Cardiovascular Angiography and Interventions, Society of Interventional Radiology (2006) ACCF/ACR/SCCT/ SCMR/ASNC/ NASCI/SCAI/SIR 2006 appropriateness criteria for cardiac computed tomography and cardiac magnetic resonance imaging: a report of the American College of Cardiology Foundation Quality Strategic Directions Committee Appropriateness Criteria Working Group, American College of Radiology, Society of Cardiovascular Computed Tomography, Society for Cardiovascular Magnetic Resonance, American Society of Nuclear Cardiology, North American Society for Cardiac Imaging, Society for Cardiovascular Angiography and Interventions, and Society of Interventional Radiology. J Am Coll Cardiol 48:1475-1497

13. Budoff MJ, Achenbach S, Blumenthal RS, Carr JJ, Goldin JG, Greenland P, Guerci AD, Lima JA, Rader DJ, Rubin GD, Shaw LJ, Wiegers SE, American Heart Association Committee on Cardiovascular Imaging and Intervention, American Heart Association Council on Cardiovascular Radiology and Intervention, American Heart Association Committee on Cardiac Imaging, Council on Clinical Cardiology (2006) Assessment of coronary artery disease by cardiac computed tomography: a scientific statement from the American Heart Association Committee on Cardiovascular Imaging and Intervention, Council on Cardiovascular Radiology and Intervention, and Committee on Cardiac Imaging, Council on Clinical Cardiology. Circulation 114:17611791
14. Schmitt R, Froehner S, Brunn J, Wagner M, Brunner H, Cherevatyy O, Gietzen F, Christopoulos G, Kerber S, Fellner F (2005) Congenital anomalies of the coronary arteries: imaging with contrast-enhanced, multidetector computed tomography. Eur Radiol 15:1110-1121

15. Schmid M, Achenbach S, Ludwig J, Baum U, Anders K, Pohle K, Daniel WG, Ropers D (2006) Visualization of coronary artery anomalies by contrastenhanced multi-detector row spiral computed tomography. Int J Cardiol 111:430-435

16. Shi H, Aschoff AJ, Brambs HJ, Hoffmann MH (2004) Multislice CT imaging of anomalous coronary arteries. Eur Radiol 14:2172-2181

17. Budoff MJ, Cohen MC, Garcia MJ, Hodgson JM, Hundley WG, Lima JA, Manning WJ, Pohost GM, Raggi PM, Rodgers GP, Rumberger JA, Taylor AJ, Creager MA, Hirshfeld JW Jr, Lorell BH, Merli G, Rodgers GP, Tracy CM, Weitz HH; American College of Cardiology Foundation; American Heart Association; American College of Physicians Task Force on Clinical Competence; American Society of Echocardiography; American Society of Nuclear Cardiology; Society of Atherosclerosis Imaging; Society for Cardiovascular Angiography \& Interventions; Society of Cardiovascular Computed Tomography (2005) ACCF/ AHA clinical competence statement on cardiac imaging with computed tomography and magnetic resonance. Circulation 112:598-617

18. Angelini P, Velasco JA, Flamm S (2002) Coronary anomalies: incidence, pathophysiology, and clinical relevance. Circulation 105:2449-2454

19. Cheng TO (1997) Prevalence and relevance of coronary artery anomalies. Cathet Cardiovasc Diagn 42:276-277

20. Heart disease and stroke statistics 2005 update (2005) American Heart Association, Dallas, Texas

21. Becker AE (1995) Congenital coronary arterial anomalies of clinical relevance. Coron Artery Dis 6:187-193 
22. Maron BJ, Thompson PD, Puffer JC, McGrew CA, Strong WB, Douglas PS, Clark LT, Mitten MJ, Crawford MH, Atkins DL, Driscoll DJ, Epstein AE (1996) Cardiovascular preparticipation screening of competitive athletes: a statement for health professionals from the Sudden Death Committee (Clinical Cardiology) and Congenital Cardiac Defects Committee (Cardiovascular Disease in the Young), American Heart Association. Circulation 94:850-856

23. Baltaxe HA, Wixson D (1977) The incidence of congenital anomalies of the coronary arteries in the adult population. Radiology 122:47-52

24. Click RL, Holmes DR Jr, Vlietstra RE, Kosinski AS, Kronmal RA (1989) Anomalous coronary arteries: location, degree of atherosclerosis and effect on survival-a report from the Coronary Artery Surgery Study. J Am Coll Cardiol 13:531-537

25. Yamanaka O, Hobbs RE (1990) Coronary artery anomalies in 126,595 patients undergoing coronary arteriography. Cathet Cardiovasc Diagn 21:28-40

26. Samdarshi TE, Mahan EF III, Nanda NC, Sanyal RS (1991) Transesophageal echocardiographic assessment of congenital coronary artery to coronary sinus fistulas in adults. Am J Cardiol 68:263-266
27. Post JC, van Rossum AC, Bronzwaer JG, de Cock CC, Hofman MB, Valk J, Visser CA (1995) Magnetic resonance angiography of anomalous coronary arteries. A new gold standard for delineating the proximal course? Circulation 92:3163-3171

28. Pouleur AC, le Polain de Waroux JB, Kefer J, Pasquet A, Coche E, Vanoverschelde JL, Gerber BL (2007) Usefulness of 40-slice multidetector row computed tomography to detect coronary disease in patients prior to cardiac valve surgery. Eur Radiol 17:3199-3207

29. Scheffel H, Alkadhi H, Plass A, Vachenauer R, Desbiolles L, Gaemperli O, Schepis T, Frauenfelder T, Schertler T, Husmann L, Grunenfelder J, Genoni M, Kaufmann PA, Marincek B, Leschka S (2006) Accuracy of dualsource CT coronary angiography: first experience in a high pre-test probability population without heart rate control. Eur Radiol 16:2739-2747

30. Austen WG, Edwards JE, Frye RL, Gensini GG, Gott VL, Griffith LS, McGoon DC, Murphy ML, Roe BB (1975) A reporting system on patients evaluated for coronary artery disease. Report of the Ad Hoc Committee for Grading of Coronary Artery Disease, Council on Cardiovascular Surgery, American Heart Association. Circulation 51:5-40
31. Alderman E, Stedius M (1992) The angiographic definitions of the Bypass Angioplasty Revascularization Investigation study (BARI). Coron Artery Dis 3:1189-1207

32. Scanlon PJ, Faxon DP, Audet AM, Carabello B, Dehmer GJ, Eagle KA, Legako RD, Leon DF, Murray JA, Nissen SE, Pepine CJ, Watson RM, Ritchie JL, Gibbons RJ, Cheitlin MD, Gardner TJ, Garson A Jr, Russell RO Jr, Ryan TJ, Smith SC Jr (1999) ACC/ AHA guidelines for coronary angiography. A report of the American College of Cardiology/American Heart Association Task Force on practice guidelines (Committee on Coronary Angiography). Developed in collaboration with the Society for Cardiac Angiography and Interventions. J Am Coll Cardiol 33:1756-1824

33. Pannu HK, Jacobs JE, Lai S, Fishman EK (2006) Coronary CT angiography with 64-MDCT: assessment of vessel visibility. AJR Am J Roentgenol 187:119-126

34. Levin DC, Fallon JT (1982) Significance of the angiographic morphology of localized coronary stenoses: histopathologic correlations. Circulation 66:316-320

35. Mohlenkamp S, Hort W, Ge J, Erbel R (2002) Update on myocardial bridging. Circulation 106:2616-2622 